Session 3249

\title{
Women in Engineering Technology: Where are they?
}

\author{
Timothy Brower, Harriet Cornachione \\ Oregon Institute of Technology
}

\begin{abstract}
Despite substantial increases in the number of women entering law, medicine, and businessfields previously dominated by men, there is still a scarcity of women in the field of engineering. Women continue to lag behind men in their enrollment into engineering programs and, consequently, in their completion of engineering degrees. At Oregon Institute of Technology (Oregon Tech) the disparity is especially acute in the engineering technology programs. One student-led initiative implemented to remedy Oregon Tech's situation was with a diversity action grant obtained by the American Society of Mechanical Engineers (ASME) student club. The ASME students, working in conjunction with the Society of Women Engineers (SWE) club, developed and administered a one-day conference designed specifically for female high school students regarding engineering careers. A successful program resulted that has helped to focus attention on possible reasons for the disparity of women in engineering technology. In addition, from the collaborative effort of the ASME and SWE clubs, strategies have been conceived for the recruitment and retention of women in engineering programs at Oregon Tech.
\end{abstract}

\section{Introduction}

Oregon Institute of Technology (Oregon Tech) is part of the public Oregon University System enrolling approximately 2500 students. Located in southernmost Oregon, just east of the Cascade Range, the college is central to an extensive rural population from which it draws a large percentage of its students. Oregon Tech consists of the School of Engineering, Technology $\&$ Management (ETM) and the School of Health and the Arts \& Sciences (HAS). ETM offers 12 undergraduate 4-year Bachelor of Science Degree Programs accredited through the Accrediting Board for Engineering and Technology (ABET) housed in the following departments:

- Civil Engineering \& Geomatics,

- Computer Systems Engineering Technology,

- Electronics Engineering Technology,

- Management, and

- Manufacturing \& Mechanical Engineering Technology.

In the Fall of 1999, after a lengthy transition period to a Bachelor of Civil Engineering (BCE) from a Bachelor of Civil Engineering Technology (BCET) degree program, the Civil Engineering \& Geomatics Department (CE\&G) received accreditation of the BCE degree by the Engineering Accreditation Commission (EAC) of ABET. The Bachelor of Surveying Degree Program offered by CE\&G is accredited by the Related Accreditation Commission (RAC) of

"Proceedings of the 2001 American Society for Engineering Education Annual Conference \& Exposition Copyright @ 2001, American Society for Engineering Education" 
ABET. All other departments offer bachelor degree programs in engineering technology and are accredited by the Technology Accreditation Commission (TAC) of ABET. Programs in the Department of Management are an exception and do not fall under the purview of the ABET accreditation system and are not considered here.

Literature pertaining to issues surrounding recruitment and retention of women in engineering and engineering technology (ET) programs typically does not distinguish between engineering and ET degree programs. Having both engineering and ET programs resident on the same campus, coupled with the recent change from a BCET to a BCE program provides Oregon Tech with a unique perspective to study differences between women in engineering and women in ET degree programs. Further, it is important in recruitment and retention efforts to identify any differences that may exist.

Oregon Tech identified increasing minority students as one of the primary institutional goals in its 1994-1999 Strategic Plan ${ }^{1}$. Among other specific objectives in this plan, increasing the numbers of women students enrolled in the ET programs was an established priority. Two formal pre-college Women-In-Engineering (WIE) programs are offered at Oregon Tech in direct support of this objective. More recently, a "student-led" WIE initiative was implemented in the spring of 2000 to encourage high school women to consider engineering or ET in their career choice. This latter WIE effort is a primary focus of this paper.

Despite a nominal priority of increasing the numbers of women entering and completing degrees in the fields of engineering and ET, and supporting this goal through various programs, Oregon Tech statistics do not reflect significant positive change over the years. Many students and faculty are cognizant of this, and consider it an area demanding improvement.

The objectives of this paper are:

- to review the recent statistics related to women enrolling in engineering and ET degree programs as compared with national statistics,

- to present a new student-led pre-college initiative in the recruitment of women into engineering and ET degree programs, and,

- to identify issues related to the retention of the women entering these fields.

It is hoped that a presentation and discussion of these issues at Oregon Tech will help other small engineering technology schools to further their efforts in attracting and retaining women in their engineering and ET programs.

\section{Historical Perspective: The Numbers}

In attempting to quantify the impact of any WIE program, such as the student led initiative described in this paper, a background perspective of women enrolled at Oregon Tech is important. In this light, both national and institution-specific data is desirable. Although accurate data has been difficult to obtain at Oregon Tech in previous years, a recent Title III Grant $^{2}$ has helped to develop a student enrollment database. Data on women enrolled at Oregon 
Tech in engineering and ET programs have been identified and can be accurately tracked since 1998.

Nationally, the percentage of undergraduate bachelor degrees awarded to women in engineering and ET programs has slowly climbed over the past 10 years ${ }^{3}$, and was approximately $21 \%$ in $1999^{4}$. In order to compare to the national percentages, Oregon Tech enrollment data provided in Table I, shows women students in engineering and ET majors for the fall of 1998, 1999 and 2000. National percentages do not distinguish between engineering and ET and are for degrees awarded, however, are deemed appropriate to compare with enrollment figures at Oregon Tech.

Table I. Female Engineering and ET Students at Oregon Tech ${ }^{5}$

\begin{tabular}{|l|r|r|r|r|r|r|r|r|r|}
\hline \multirow{2}{*}{ Discipline } & \multicolumn{3}{|c|}{ Female Students* } & \multicolumn{2}{|c|}{ Total Enrolled* } & \multicolumn{3}{c|}{$\begin{array}{l}\text { Women } \\
\text { Oregon Tech/National }\end{array}$} \\
\cline { 2 - 11 } & 1998 & 1999 & 2000 & 1998 & 1999 & 2000 & 1998 & 1999 & 2000 \\
\hline Civil Engineering & 18 & 24 & 24 & 101 & 122 & 120 & $18 / 21$ & $20 / 23$ & 20 \\
\hline Civil Engr Tech & 1 & 0 & 1 & 18 & 3 & 1 & 6 & 0 & 100 \\
\hline Surveying & 5 & 5 & 6 & 56 & 46 & 52 & 9 & 11 & 12 \\
\hline Mechanical Engr Tech & 8 & 5 & 2 & 142 & 126 & 101 & $6 / 12$ & $4 / 15$ & 2 \\
\hline Manufacturing Engr Tech & 1 & 15 & 10 & 44 & 105 & 80 & 2 & 14 & 13 \\
\hline Computer Engr Tech & 15 & 22 & 15 & 165 & 204 & 210 & 9 & 11 & 7 \\
\hline Software Engr Tech & 19 & 12 & 15 & 168 & 161 & 203 & 11 & 7 & 7 \\
\hline Electronics Engr Tech & 5 & 5 & 3 & 92 & 93 & 74 & $5 / 12$ & 5 & 4 \\
\hline Laser Optical Engr Tech & 6 & 6 & 7 & 34 & 31 & 35 & 18 & 19 & 20 \\
\hline \hline TOTAL Undergraduate students at Oregon Tech, Klamath Falls campus \\
$4^{\text {th }}$ week of Fall Quarter.
\end{tabular}

The data contained in Table I shows that the population of women enrolled in Oregon Tech engineering and ET disciplines over the past three years averages about $10 \%$, only half that of the national average. However, the Mechanical Engineering Technology (MET) and the Electronics Engineering Technology (EET) degree programs are approximately half again of that population and in decline. It is noteworthy that the civil engineering numbers are at a $20 \%$ population, much closer to the national averages than those of MET or EET. These data suggest a distinct difference between the number of women in engineering versus an ET program, but could also reflect interest or familiarity with the CE field. A potential clearly exists to increase the female population in MET and EET, with a goal of approaching the school average of 8 $11 \%$ female students seemingly a realistic target for the future. National percentages in mechanical and electrical engineering are between $12-15 \%$, further affirming this goal.

\section{Pre-College Recruiting Strategies at Oregon Tech}

In order to provide career guidance and engineering educational programs for junior high and high school students that includes a strong component targeting female participation, two 
programs at Oregon Tech have been ongoing. "Expanding Your Horizons" (EYH) is a program targeting all 8th grade girls from an extended local area (50-plus mile radius from the Oregon Tech campus) offered every February. "Teen Women in Science and Technology" (TWIST) is a week long residential program targeting entering high school sophomore girls, with an opportunity for students to return as junior counselors in their pre-junior and/or pre-senior high school years.

Unfortunately, only limited statistics and tracking of students who attended one or more of Oregon Tech's EYH and TWIST programs are available. Anecdotal evidence suggests that the programs have an impact on the decision process which young women follow in selecting both their career goals and their college programs of study. Based on this type of evidence, and a strong belief that it is "the right thing to do" in helping to prepare 7-12 grade students for a wide career choice in college, the programs have continued to be offered. Indeed, additional programs open to all genders have been added. However, adult professionals and adult educators offer all of the programs today and are generally gender-specific, i.e., female presentations to girls, etc., with little or no college-student input or participation. Minimal follow-up is performed within the schools or one-on-one with the participants.

Hence, when the national organization of the ASME offered the Diversity Action Grant (DAG) Program, student members, in cooperation with their faculty advisor responded with a proposal. The proposal sought funding for additional recruitment activities specifically to enhance female enrollment in the MET program at Oregon Tech.

\section{ASME DAG Project ${ }^{8}$}

\section{Project Goals \& Objectives}

Weekly ASME student meetings at Oregon Tech reflect the lack of gender diversity in the MET Department. This observation drove the DAG project goal of expanding and encouraging gender diversity within the MET program at Oregon Tech. The specific objectives proposed to accomplish this goal were:

- to develop a partnership with the SWE club at Oregon Tech, and,

- to develop and host a "Women-In-Engineering" conference for local/regional female high school students, in which professional female engineers were participants.

\section{Project Overview}

Several joint meetings were conducted between the ASME and SWE at Oregon Tech to explore a collaborative effort on the administration of the DAG. SWE members were receptive to the proposal and provided input to assist with development of the final program components. SWE members also provided support for the program through their participation in the conference.

The conference entitled "Women-In-Engineering" was held at Oregon Tech during the spring 2000 quarter for interested regional and local high school students. The conference featured three concurrent sessions presented by the SWE students, the ASME students, and the ASME faculty advisor. High school students attended all three sessions accompanied by the female 
professional engineers, faculty and college students. The student sessions featured hands-on workshops, and the professor-led session presented three different senior projects ongoing in the MET department. Specific program components are detailed in the appendix. After the three engineering workshop presentations, tours of the student residence hall facilities took place. The culmination of the high school student's day at Oregon Tech was a banquet dinner that evening.

After the dinner, a panel of three professional women engineers, two women engineering students from the MET program and one from the CE program was assembled. Questions from the audience ranged from detailed aspects of engineering fields or careers and why the panelists chose their specific discipline, to the pitfalls encountered along the way to obtaining an engineering degree. A survey was administered toward the end of the program to all participants and attendees.

\section{Project Results}

The "Women-In-Engineering" conference drew female high school students from two city, three county and one regional high schools, for a total of 41 participants. Five professional female engineers from various engineering disciplines participated. Eight SWE students (all female) and 10 ASME students (all male) were present as well as 6 women engineering and science faculty and 1 male engineering professor from Oregon Tech. The conference was open to all freshmen through senior high school females. A breakdown of the high school students that participated is shown in Fig. 1.

Overall the post-conference surveys indicated that the program was successful in providing attendees with a better understanding of engineering as a career (Fig. 2). Attendees also were somewhat more likely to consider engineering as a possible personal career choice (Fig. 3). In attempting to determine which facets of the program had the greatest impact on the students, questions were asked which provided information for future conferences. The question, "Which conference participants had the most influence on you for considering engineering as a career?" revealed that the students clearly related to the current
Figure 1. Conference Participant Information: What is your grade in high school?

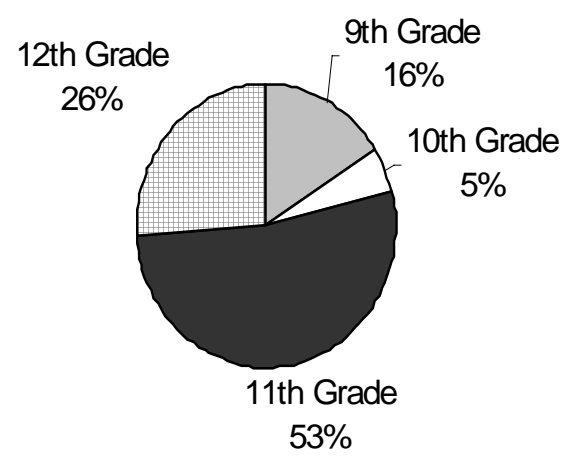

Figure 2. Survey Questionnaire:

I consider my knowledge of engineering as a career to be:

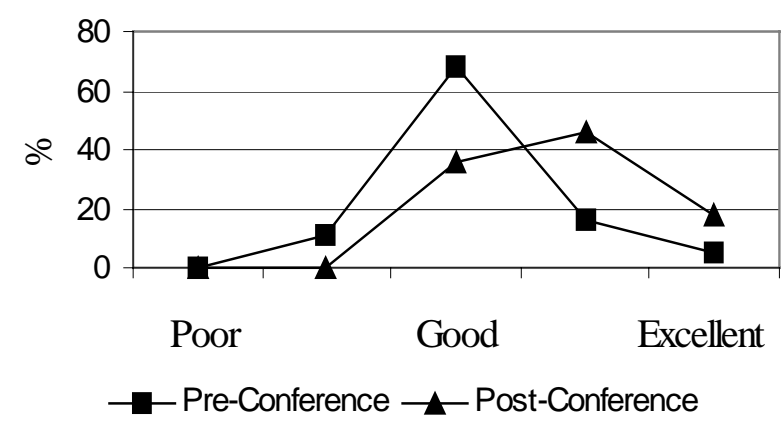


women engineering students, as is shown by the graph in Fig. 4, with female professionals a close second.

Not surprisingly, as the literature suggests,

Figure 3. Survey Questionnaire: role models to whom the high school students can directly relate is very important in influencing young women in careers $^{9}$. Interestingly and in contrast, experience in advising the SWE club on campus suggests that few women engineering students feel compelled to join a gender-specific professional group once they have begun their studies. Various reasons are cited, ranging from a lack of time, to the preference of joining a club directly related to their major discipline, to a desire to fit in with the "whole group" not just women.

\section{Project Impacts at Oregon Tech}

It is still early to expect a substantial and direct benefit of added female students enrolling in engineering programs at Oregon Tech, however, the project provided some benefits that should enhance the attractiveness of the programs and discipline for women. The ASME students gained a better understanding of some of the concerns facing women students in choosing engineering as a career, as well as some concerns and positive indicators for MET as a field. The SWE and ASME clubs continue to collaborate and plan to offer a similar program in the spring of 2001, making I will consider engineering as a career:

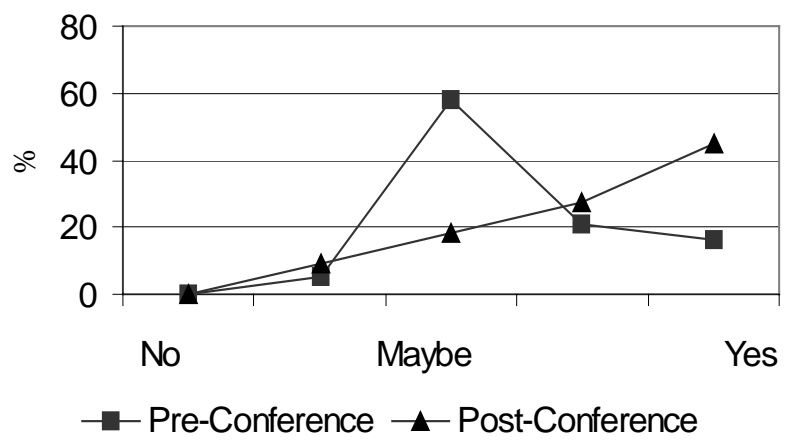

Figure 4. Survey Questionnaire:

Conference participants that had the most influence on you for considering engineering as a career:

adjustments based on the feedback from

the surveys. In addition, the clubs have collaborated on other events, both service-oriented and social in nature. For the health of gender diversity on the Oregon Tech campus, this is a great step forward.

The students in both the SWE and ASME clubs began to take ownership of their professional careers and their budding responsibility to "uphold their profession" to the public with this project. A major mission and objective of the SWE national organization has always been to promote engineering and engineering education. With this project, the student club saw the value of this objective, and also saw the impact they could have even as college students, on 
younger women. Additionally, they expressed much appreciation for the opportunity to discuss career issues with the working professionals. As a result, the campus SWE club is currently rethinking its objectives and considering various programs that they can develop and provide in the local K-12 system, or at their own high school alma mater.

\section{Retention of Women Recruited}

A continuing challenge for all engineering and ET programs remains the retention of women through graduation. There are two approaches to this challenge that have been used at Oregon Tech. The first, and perhaps in the long term, the most important, has been the primary subject of this paper. That is the education of female students in the K-12 system. Programs that offer early intervention promoting engineering as a viable and exciting career field has been demonstrated to be effective numerous times ${ }^{10}$. These programs can also help the student develop realistic expectations of the nature of study required to obtain an engineering degree.

For an institution of higher education serving a primarily rural, first-generation college student populous ( $64 \%$ of the students at Oregon Tech are first-generation ${ }^{11}$ ), these programs have merit for both young women and young men, because they promote the field as available to all students. In addition, this helps instill the expectation of a diverse population in the classroom as well as the workplace. It is hoped that these kinds of programs will have a powerful longterm impact on the numbers of young women entering the field of engineering, and the numbers of women remaining in that field after graduation.

A second issue is more immediate, that being intervention strategies that can help the student who has chosen to pursue an engineering or ET degree graduate from that program. Typically the SWE clubs have been promoted as a starting point for retention programs for women in engineering majors. The experience at Oregon Tech has been that this vehicle has limited success. In particular, many women students, particularly in their freshman year, choose not to join this organization. SWE at Oregon Tech, reactivated about eight years ago, has not had any participation from women MET majors.

With the current small group of women students in the ETM programs, a "critical mass" seems unreachable, at least in order to offer programs of wide interest and impact. For those students who do join the club however, the organization seems to function very effectively. Not only does the club provide a technical support network for students, but when gender-related or life problems occur which threaten the student's ability to complete their program of study the group is invaluable. The program described in this paper has infused energy into the current SWE club members at Oregon Tech, who have become interested in reaching out to younger female students about careers in engineering. The ability to see themselves as mentors with experiences, skills and knowledge that can help guide others has increased the self-efficacy for all those who participated.

Two retention issues apparently dominate for many women in engineering programs at Oregon Tech, according to verbal comments made in SWE meetings, advisor offices, and exit interviews. First, the lack of preparation for the classroom rigor and demands of college level 
curricula makes the early year(s) in the program too discouraging for many women. In part this can be due to their self-imposed expectations. This problem is coupled with (possibly perceived) offensive attitudes on the part of the male students and primarily male faculty in and out of the classroom.

Continuation of the SWE club efforts and increased mentoring are current goals to help relieve the first issue, lack of academic preparation. In addition, SWE is making increased efforts at collaboration with ASME and other engineering-related clubs on campus. These efforts can only help diffuse, and perhaps in time alleviate the latter issue for many women students. More direct communication between genders, disciplines and with faculty is seen as an attainable goal for this small campus, and is considered a long-term goal to boost retention.

\section{Concluding Remarks}

As Oregon Tech struggles to increase its enrollment of women in its engineering programs, we ask ourselves questions such as:

1) Is the disparity between the numbers of women in the engineering program, i.e., the CE program, compared to those in the ET programs due to the inherent differences in the perception of what ET is? ET is typically portrayed as a "hands-on" discipline where you get dirty. At Oregon Tech, the emphasis and strength of the curriculum are laboratory intensive courses rather than a purely theoretical bent. This approach helps the student better understand the engineering science principles involved, and, facilitates the student's transition to industry, which is part of the Oregon Tech mission. However, this approach may "backfire" in our recruiting of women students.

2) Are the underlying reasons for low women percentages in certain ET disciplines our faculty's and male student's fault as a result of a "gendered apartheid system ${ }^{12}$ ?" The myth that engineering is only associated with construction, machinery, and working under your car and is seen as more masculine than other careers is certainly being perpetuated with some recruiting methods of fellow faculty. One remedy being discussed to promote gender equity is for the ASME/SWE student clubs to sponsor a diversity training session for the students as well as the faculty.

3) Are we caught in a Catch-22 in the ET programs in that the lack of women in ET is responsible for the lack of women in ET? Is it necessary to reach a critical mass of female students and faculty to attract additional female students and faculty? [As an important sidenote, the MET and EET programs do not have any female faculty members.]

\section{Acknowledgements}

The authors would like to gratefully acknowledge the American Society of Mechanical Engineers Diversity Action Program and Oregon Institute of Technology's Commission on College Teaching for their financial support. 
Bibliography

1. Oregon Institute of Technology Strategic Plan, 1994 -1999, Klamath Falls, OR.

2. Title III Project, Federal Grant to Oregon Institute of Technology, 5-yr. duration received in 1998.

3. Science \& Engineering Indicators, 1998.

4. ASEE Prism, September 2000.

5. Oregon Institute of Technology "Fact Book," prepared by Title III Project Staff, August 1998, 1999, and 2000.

6. Engineering and Technology Degrees, 1998, AAES, Engineering Workforce Commission.

7. Conachione, H.S., Cornachione, M.A., and Vance, V.J., "Waterworks: A Summer Workshop for High School Girls," Proceedings AWRA/UCOWR Symposium, Keystone, CO, June 29-July 3, 1997.

8. Hill, D., Noble, K. and Brower, T., "Final Report to the ASME Board on Minorities and Women," ASME Diversity Action Grant, Oregon Institute of Technology, June 2000.

9. URL: http://www.wepan.org; WEPAN Role Models.

10. Blaisdell, S. and Anderson-Rowland, M.R., "Wise-Up: A Foundation Coalition Effort to Recruit Women into Engineering," Impacting Change Through Collaboration: 1997 WEPAN/NAMEPA Conference.

11. Hancock, J.E., Oregon Institute of Technology TRIO Grant Results.

12. Athena Unbound: The Advancement of Women in Science and Technology, Cambridge University Press, 2000 .

TIMOTHY L. BROWER is an assistant professor in the Depart of Manufacturing and Mechanical Engr. Tech. He received his BS in General Engr. at Idaho State Univ., an MS in Mechanical Engr. from Montana State Univ. and a Ph.D. in Civil Engr. from Colorado State Univ. Before teaching at Oregon Tech two years ago, he worked as an aerospace engineer with the Lockheed Martin Corporation in Denver, Colorado. Dr. Brower is a member of the ASME and faculty advisor for that club. He also is a member of ASEE and AIAA.

HARRIET S. CORNACHIONE is an associate professor in the Department of Civil Engr. \& Geomatics at Oregon Institute of Technology, where she teaches geotechnical, environmental and introductory engineering courses. She is a member of ASEE and the Association of Engineering Geologists, and serves as the faculty advisor to the Society of Women Engineer's club at Oregon Tech. 


\section{APPENDIX “Women-In-Engineering” Conference}

\section{Program Components:}

\section{(1) SWE member workshop entitled, "Chocolate Concrete Cookies."}

The SWE member presentation was intended to simulate the process of making asphalt pavement. Aggregate consisted of oatmeal, coconut, and thick syrup. Students were able to make their own mix. A pop can was used to simulate the roller to compact the mixture. All this contributed to the essence of how to build a road. Slides of an actual road being constructed were shown at the conclusion of the demonstration. Participants took their creation away with them.

\section{(2) ASME member workshop entitled, "The Ultimate Squirt Gun."}

The ASME member presentation was conducted in the machine shop on campus and was intended to be interactive and fun. The goal was to have the female high school students build simple water guns with PVC pipe parts. The parts required some modifications in order for the water cannon to work properly. The manufacturing of the various parts was not the primary concentration of the presentation. It was found that many students weren't aware of what a mechanical engineer does. The intention of the ASME presentation was to familiarize the students with the many types of careers that a mechanical engineer might hold. Emphasis was placed on everything from a design to a sales engineer. The water cannons assembled by the female students were used to illustrate the different types of engineering that can be done to a simple machine. The topics included fluid mechanics, manufacturing engineering, machine design techniques and computer software. Each high school student was able to take their twofoot long by 11/4-inch diameter squirt gun they made home with them.

\section{(3) Three different senior projects presented by the mechanical engineering technology} students were presented. These included:

- A group of six students participated in NASA's Reduced Gravity Student Flight Opportunities Program by taking an experiment up on the NASA KC-13A out of Houston, Texas. These students flew up to 60 parabolic trajectories, each having about a half minute of zero gravity, where they conducted low gravity experiments concerning bubble migration. A video of the flight was shown.

- A group of two students are building a wine-fermenting device that can be marketed to wineries across the country. The actual tank was shown and described.

- A group of four students are working with the company Alcatel Submarine Networks and designing and testing a hermetic cable joint. A storyboard showing the materials used and methods of construction in this project was shown. 